\title{
Pengaruh Organizational Citizenship Behavior pada Performance dengan Service Quality, Satisfaction dan Behavior Intention Sebagai Anteseden
}

\author{
Joko Suyono \\ Universitas Negeri Sebelas Maret \\ Sinto Sunaryo* \\ Universitas Negeri Sebelas Maret
}

\begin{abstract}
The purpose of the study is to observe the influence of organizational citizen behavior to performance. Organizational citizen behavior is affected by three variables namely satisfaction, service quality and behavior intention. The study was conducted on 12 nurses, 128 patients, and 10 nursing supervisor at a private hospital in Surakarta, Jawa Tengah. Stratified random sampling technique was applied to determine the number of sample. The result was based on structural equation modeling (SEM) method that showed there is no relationship between OCB and satisfaction and OCB to behavior intention. On the other hand, OCB to customer satisfaction, OCB to performance and satisfaction to performance are proved to be significant.
\end{abstract}

Keywords: $O C B$, service quality, satisfaction, behavior intention and performance

\section{PENDAHULUAN}

Aktifitas karyawan pada suatu organisasi jasa menghubungkan organisasi dengan konsumen mereka (Gronroos, 1990). Aktifitas ini bertujuan untuk menjaga loyalitas konsumen dengan cara memberikan apa yang telah dijanjikan kepada konsumen (Berry, 1995). Hal ini merupakan hal yang penting dalam mengembangkan hubungan kerja yang efektif dengan konsumen (Gwinner, Gremler \& Bitner, 1998). Karyawan dari suatu organisasi menjadi hal penting untuk menentukan keberhasilan suatu organisasi karena merekalah yang bertanggungjawab untuk memberikan pelayanan yang berkualitas sesuai dengan apa yang diharapkan konsumen (Boulding, Kalra, Staelin, \& Zeithaml, 1993; Parasuraman, Zeithaml, \& Berry, 1991; Zeithaml, Berry \& Parasuraman, 1996). Keterampilan, sikap mereka, peralatan dan alat pendukung yang tersedia untuk meningkatkan pelayanan merupakan faktor-faktor pokok penentu loyalitas konsumen.

\footnotetext{
* Korespondensi: Sinto Sunaryo, Jurusan Manajemen, Fakultas Ekonomi dan Bisnis, Universitas Negeri Sebelas Maret, Jalan Ir. Sutami No. 36A Kentingan, Surakarta 57126, Indonesia. Email: sintosunaryo@yahoo.com
} 
Penelitian terbaru di bidang pemasaran telah difokuskan pada pengaruh keterampilan dan perilaku karyawan pada loyalitas konsumen (Reichheld, Reynold \& Beatty dalam Castro \& David, 2004). Dalam perkembangan selanjutnya, penelitian yang dilakukan dikaitkan dengan konsep organizational citizenship behavior (OCB) sebagai alat untuk menganalisa pengaruh perilaku pada kinerja organisasi (MacKenzie, Podsakoff \& Ahearne, 1998).

Beberapa studi berusaha untuk mengukur pengaruh variabel-variabel tertentu dari organisasi terhadap tanggapan konsumen (Babin \& Boles, 1998; Brown \& Peterson, 1993). Namun demikian, hampir semua penelitian tersebut berfokus menyelidiki pengaruh "peran" perilaku karyawan pada persepsi konsumen mengenai kualitas pelayanan yang mereka terima. Tujuan penelitian ini adalah menganalisis perilaku individu yang lebih luas cakupannya dari standar normal yang diharapkan karyawan, yang dikenal sebagai OCB. Penelitian ini berfokus pada hubungan yang kompleks antara perilaku karyawan dan kinerja suatu organisasi. Penelitian ini semakin menarik karena menitikberatkan pada analisis karyawan dan konsumen untuk mengukur pengaruh perilaku pada persepsi konsumen dan kinerja organisasi. Dalam hal ini, belum banyak penelitian yang meneliti hubungan konsumen-karyawan dan pengaruhnya pada kinerja organisasi.

Sebuah rumah sakit di Surakarta, Jawa Tengah, mempunyai visi yang kuat dalam memberikan kualitas pelayanan yang terbaik kepada setiap pasiennya. Rumah sakit ini lebih condong mempertahankan kualitas jasa agar pasien tetap setia, dengan cara menekankan sisi perilaku individu internal agar memberikan pelayanan yang terbaik kepada konsumen (OCB) daripada menarik pasien baru yang lebih banyak tetapi dengan kualitas pelayananan yang stagnan. Loyalitas pasien akan berdampak pada pembuatan kebijakan rumah sakit yang menekankan pada kinerja karyawannya, baik tenaga medis maupun non medis.

Oleh karena itu, untuk mengetahui seberapa besar pengaruh kontribusi individu (perawat) dalam memenuhi tuntutan peran pada tingkat kinerja mereka dalam memberikan pelayanan terbaik kepada pasien, diperlukan penelitian yang lebih dalam untuk mengkaji hal tersebut.

\section{TINJAUAN PUSTAKA}

\subsection{Satisfaction}

Keberhasilan suatu organisasi sangat dipengaruhi oleh cara organisasi tersebut memuaskan pelanggan, baik internal maupun eksternal. Organisasi, sebagai individu dalam suatu sistem, memfokuskan kegiatan pada pelanggan eksternal, agar dapat lebih efektif dan efisien dalam menjalankan kegiatannya. Pada pihak lain, organisasi sebagai suatu sistem, juga harus memuaskan pelanggan internal (karyawan) agar dapat memberikan layanan yang berkualitas, karena karyawan berfungsi sebagai produsen jasa. 
Pelayanan kepada pelanggan sebaiknya diarahkan pada pelayanan yang berkesinambungan, bahkan sampai seumur hidup. Organisasi sebaiknya memfokuskan aktivitas pada rantai nilai (value chain), yang dapat menghasilkan pelayanan yang berkualitas. Dengan berfokus pada pelanggan, organisasi menjadi lebih efektif dan kepuasan pelanggan dapat dicapai optimal (Kotler, 2000).

Ternyata kepuasan konsumen berpengaruh secara signifikan pada kinerja operasional organisasi. Dengan menggunakan alat penilaian yang tepat, kepuasan konsumen (customer satisfaction) dapat diakses melalui penyediaan barang dan jasa serta penyediaan barang dan jasa yang cepat memenuhi harapan pelanggan (customer expectation). Ketika menciptakan kepuasan konsumen, secara umum ada dua metode: (1) Single item: mempunyai single item untuk mengakses seluruh kepuasan. Sehingga dapat dipahami bahwa dampak dari seluruh kepuasan terjadi setelah pelanggan menggunakan produk melalui item kepuasan tunggal (single satisfaction item). (2) Multiple item: mengukur kepuasan individu melalui produk dengan menggunakan skala umum (genaral scale) kemudian menjumlahkan seluruh kepuasan. Menurut pendapat Day (dalam Castro \& David, 2004), kepuasan konsumen dapat diciptakan melalui konsep yang menyeluruh dan beberapa variabel dapat digunakan untuk menciptakan kepuasan konsumen (customer satisfaction).

Menurut Kotler (2000), apakah pembeli akan puas setelah pembelian tergantung pada kinerja tawaran dalam memenuhi harapan pembeli. Secara umum, kepuasan adalah perasaan senang atau kecewa seseorang yang muncul setelah membandingkan kinerja (hasil) produk yang dipikirkan terhadap kinerja (hasil) yang diharapkan. Jika kinerja dibawah harapan, pelanggan tidak puas. Jika kinerja memenuhi harapan, pelanggan puas. Jika kinerja melebihi harapan, pelanggan amat puas atau senang.

Tautan antara kepuasan pelanggan dan kesetiaan pelanggan tidak bersifat proporsional. Andaikan kepuasan pelanggan diberi peringkat dengan skala satu sampai lima, pada level kepuasan pelanggan yang sangat rendah (level satu), para pelanggan cenderung menjauhi organisasi dan menyebarkan cerita jelek tentang organisasi tersebut. Pada level dua sampai empat pelanggan agak puas tetapi masih merasa mudah untuk beralih ketika tawaran yang lebih baik muncul. Pada level lima, pelanggan sangat cenderung membeli ulang dan bahkan menyampaikan cerita pujian tentang organisasi (Kotler, 2000).

Organisasi dapat menarik dan mempertahankan pelanggan melalui serangkaian proses. Menurut Kotler (2000), selain bekerja dengan para mitra yang disebut manajemen relasi kemitraan atau partner relationship management (PRM), banyak organisasi bermaksud mengembangkan ikatan yang lebih kuat dengan para pelanggan akhirnya disebut manajemen relasi pelanggan atau customer relationship management (CRM). Manajemen relasi pelanggan adalah proses pengelolaaan informasi yang rinci tentang masing-masing pelanggan dan mengelola secara cermat semua "titik sentuh" pelanggan dengan tujuan memaksimalkan kesetiaan pelanggan. 
Para pelanggan dewasa ini sulit terpuaskan. Mereka lebih cerdas, lebih sadar harga, lebih menuntut, kurang memaafkan dan didekati oleh banyak pesaing dengan tawaran yang sama atau lebih baik. Tantangannya menurut Gitomer (dalam Kotler, 2000), adalah bukan menghasilkan pelanggan yang puas, beberapa pesaing dapat melakukan itu. Tantangannya adalah menghasilkan pelanggan yang senang dan setia.

\subsection{Service Quality}

Penelitian PIMS (Profit Impact at Market Strategy) menunjukkan adanya korelasi kuat antara kualitas pelayanan yang diterima pelanggan dengan pangsa pasar (Hutabarat dalam Kotler, 2000). Hasil penelitian ini menunjukkan bahwa salah satu faktor yang mempengaruhi pangsa pasar adalah peningkatan kualitas pelayanan. Kualitas pelayanan menjadi pemicu keberhasilan organisasi pada segala lini. Kualitas pelayanan merupakan kewajiban bagi organisasi, baik organisasi manufaktur maupun (terutama) organisasi jasa. Heskett menyatakan pelayanan merupakan kunci sukses, sehingga kualitas pelayanan harus menjadi fokus perhatian manajemen organisasi ketika menjalankan bisnisnya. Pelayanan yang berkualitas dan memuaskan pelanggan perlu dilakukan terusmenerus, meskipun pengaduan yang diterima relatif rendah. Sekitar 95\% konsumen yang tidak puas memilih untuk tidak melakukan pengaduan, tetapi sebagian besar cukup menghentikan pembeliannya (Kotler, 2000).

Lebih lanjut Kotler (2000) menjelaskan bahwa sebuah organisasi jasa dapat memenangkan persaingan dengan menyampaikan secara konsisten layanan yang bermutu lebih tinggi dibandingkan para pesaing dan yang lebih tinggi dari pada harapan pelanggan. Harapan-harapan itu dibentuk oleh pengalaman di masa lalu, pembicaraan dari mulut ke mulut, dan iklan organisasi jasa. Setelah menerima jasa itu, pelanggan membandingkan jasa yang dialami dengan jasa yang diharapkan. Jika jasa yang dialami berada di bawah jasa yang diharapkan, pelanggan tidak berminat lagi terhadap penyedia jasa itu. Jika jasa yang dialami memenuhi atau melebihi harapan, mereka akan menggunakan penyedia jasa itu lagi.

Pasuraman, et al. (1991) membentuk model mutu jasa yang menyoroti syaratsyarat utama dalam memberikan mutu jasa yang tinggi. Dalam model ini mengidentifikasi lima kesenjangan yang mengakibatkan kegagalan penyampaian jasa, yaitu: kesenjangan antara harapan konsumen dan persepsi manajemen dimana manajemen tidak selalu memahami secara tepat apa yang diinginkan pelanggan, kesenjangan antara persepsi manajemen dengan spesifikasi mutu jasa dimana manajemen mungkin memahami secara tepat keinginan pelanggan tetapi tidak menetapkan satu kumpulan standar kinerja tertentu, kesenjangan antara spesifikasi mutu jasa dan penyampaian jasa dimana penyedia jasa mungkin kurang terlatih, tidak mampu atau tidak memenuhi standar, kesenjangan antara penyampaian jasa dan komunikasi eksternal dimana harapan konsumen dipengaruhi oleh pernyataan yang dibuat organisasi dan iklan organisasi, serta kesenjangan antara jasa yang dialami dan jasa yang diharapkan dimana 
kesenjangan ini terjadi bila pelanggan memiliki persepsi yang keliru tentang mutu jasa yang disampaikan.

Bebko (2000) mengatakan bahwa kualitas pelayanan dapat diukur dengan melihat tingkat kesenjangan antara harapan atau keinginan konsumen dengan persepsi mereka terhadap kinerja produk atau organisasi yang diterima oleh konsumen yang dapat dijelaskan dalam skala service quality (SERVQUAL scale). Penelitian menunjukkan bahwa SERVQUAL dapat menjadi alat yang efektif dan stabil untuk mengukur service quality melalui industri jasa (Pasuraman, et al., 1990). Skala ini dikembangkan dan valid digunakan sebagai prosedur di dalam empat sektor jasa, yaitu: retail banking, credit cards, securities brokerage, dan product repair and maintenance. Prosedur-prosedur diseleksi berdasarkan pada fakta bahwa mereka bervariasi pada atribut kunci scheme klasifikasi multidimensional (Lovelock dalam Pasuraman et al., 1991). Tak satupun dampak servis terjadi pada hasil (outcome) atau yang terkait dengan produk tangible, meskipun product repair termasuk dalam kepemilikan consumers tangible.

Sedangkan pengukuran service quality menurut $\mathrm{Yu}$, Chang \& Huang (dalam Castro \& David, 2004), dijelaskan ada tiga macam skala penilaian untuk service quality, yaitu SERVQUAL oleh Pasuraman et al. (1991), SERVPERF oleh Cronin \& Taylor (dalam Pasuraman et al., 1991), dan Non-Difference oleh Brown \& Peterson (1993). Brown \& Peterson (1993) membantah bahwa kalkulasi dari perbedaan skore dalam pengukuran SERVQUAL dapat mendorong terciptanya problem psychometric : dimana pengukuran dengan non-difference score akan lebih diharapkan dan diinginkan. Penelitian empiris mengindikasikan bahwa reliabilitas dari SERVQUAL akan diikuti oleh pengukuran non-difference score, SERVQUAL tidak dapat menampilkan diskriminan validity tetapi non-difference score dapat menampilkan, efek variance restriction muncul ketika menggunakan SERVQUAL dan non-difference score mengukur di luar bentuk SERVQUAL pada beberapa aspek psychometric.

Ada lima dimensi dimana konsumen dapat mengevaluasi kualitas pelayanan (service quality), yaitu: (1) Tangibles, merupakan bentuk - bentuk fasilitas fisik, peralatan , personal atau individu dan komunikasi material. (2) Reliability, kemampuan untuk membentuk atau menciptakan pelayanan yang akurat dan seperti yang dijanjikan. (3) Responsiveness, kemauan untuk membantu pelanggan dan menyediakan pelayanan yang cepat (prompt service). (4) Assurance, pengetahuan dan sikap ramah dari karyawan dan kemampuan mereka untuk menciptakan keyakinan dan kepercayaan diri. (5) Emphathy, pembawaan dan perhatian individu yang disediakan oleh organisasi terhadap pelanggan (Bebko dalam Babin \& Boles, 1998).

Pasuraman et.al (1991) juga menyatakan ada lima dimensi yang digunakan oleh pelanggan untuk menilai kualitas pelayanan pada suatu industri, yaitu: Kehandalan (reliability) merupakan suatu kemampuan untuk memberikan jasa yang dijanjikan dengan akurat dan terpercaya, dimana kinerja harus sesuai dengan harapan pelanggan yaitu ketepatan waktu, pelayanan yang sama untuk semua pelanggan tanpa ada 
kesalahan. Ketanggapan (responsiveness) merupakan suatu kebijakan untuk membantu dan memberikan pelayanan yang cepat kepada pelanggan. Jaminan/kepastian (assurance), yaitu pengetahuan dan keramahan karyawan serta kemampuan melaksanakan tugas secara spontan, yang dapat menjamin kinerja yang baik sehingga menimbulkan kepercayaan dan keyakinan pelanggan. Empati (emphaty), yaitu memberikan perhatian yang bersifat individual atau pribadi kepada pelanggan dan berupaya untuk memahami keinginan konsumen. Berwujud (tangibles), yaitu penampilan dan kemampuan sarana dan prasarana fisik yang dapat diandalkan, serta keadaan lingkungan sekitar sebagai bukti nyata dari pelayanan yang diberikan oleh pemberi jasa.

Cornell (dalam Bollino, 1999) merekomendasikan bahwa industri jasa membutuhkan pengertian yang luas tentang kualitas yang kemudian banyak digunakan untuk industri manufaktur. Zimmerman (dalam Bollino, 1999) mengambil konsep quality control yang diperoleh dari industri manufaktur dan kemudian diterapkan dalam kualitas pelayanan (service quality). Zimmerman juga menyebutkan bahwa komponen dari service quality meliputi: practicality, replikasi dari kemampuan manufaktur, immediacy, ultimate user satisfaction, dan standar korespondensi. Menurut konsep Pasuraman et.al (1991), konsumen melihat proses pembentukan service quality sebagai pemberdayaan atribut interior dan eksterior dari kualitas produksi atau service quality level bawah, melalui perbandingan unit - unit internal dan merupakan proses dalam membangun level yang lebih tinggi dari kualitas pelayanan yang diterima (perceived service quality).

\subsection{Performance}

Kinerja merupakan hasil pekerjaan yang sesuai dengan tujuan organisasi misalnya kualitas kerja, kuantitas kerja, efisiensi, dan kriteria efektivitas lainnya (Gibson et al., 1997). Selain itu kinerja merupakan gabungan dari 3 faktor penting, yaitu kemampuan dan minat seorang pekerja, kemampuan dan penerimaan atas penjelasan delegasi tugas, serta peran dan tingkat motivasi seorang pekerja. Semakin tinggi ketiga faktor diatas maka semakin besar pula kinerja karyawan yang bersangkutan (Hasibuan, 2001).

Rotundo \& Sacket (2002) menyatakan terdapat tiga kelompok perilaku yang merupakan domain kinerja. Perilaku tersebut meliputi kinerja tugas, citizenship, dan kontraproduktif (counterproductive). Konsep kinerja tersebut dapat juga dikelompokkan menjadi kinerja in-role dan kinerja extra-role. Kinerja extra-role adalah perilaku yang bukan merupakan bagian dari tugas yang telah dipersyaratkan secara formal bagi seorang karyawan tetapi secara keseluruhan mendorong fungsi efektif organisasi (Robbins, 2001). Sedangkan kinerja tugas (in-role performance) dapat dikonseptualisasikan berbeda-beda, namun masing-masing konseptualisasi itu mengacu pada kelompok perilaku yang terlibat dalam penyelesaian tugas (Rotundo \& Sacket, 2002). Kinerja tugas 
meliputi dua ciri sentral. Kinerja menyaratkan aktivitas yang berkontribusi pada inti teknis (proses dimana bahan mentah dikonversi ke dalam produk spesial organisasi), dan diakui secara formal sebagai bagian dari pekerjaan. Pengertian "berkontribusi pada inti teknis" merupakan ciri penting yang dapat membantu membedakan komponen kinerja ini dari yang lainnya, tetapi persyaratan kedua bahwa "perilaku diakui secara formal sebagai bagian dari pekerjaan" membuat hal itu sulit untuk membandingkan kinerja tugas lintas organisasi. Hal ini disebabkan persyaratan formal dari satu organisasi dengan organisasi lainnya bervariasi. Menurut Welbourne et al. (1998), kinerja tugas didefinisikan sebagai pemenuhan tugas dan tanggung jawab berkaitan dengan jabatan tertentu.

\subsection{Organizational Citizenship Behaviour (OCB)}

Menurut Allen \& Rush (1998), Organizational Citizenship Behavior merupakan kontribusi individu dalam melebihi tuntutan peran di tempat kerja. OCB ini melibatkan beberapa perilaku meliputi perilaku suka menolong orang lain, menjadi volunteer untuk tugas-tugas ekstra, patuh terhadap aturan-aturan dan prosedur-prosedur di tempat kerja. Perilaku ini menggambarkan nilai tambah karyawan yang merupakan salah satru bentuk perilaku prososial, yaitu perilaku social yang positif, konstruktif dan bermakna membantu.

Organ (dalam McKenzie \& Podsakoff, 1998) mendefinisikan OCB sebagai perilaku individual yang bersifat bebas (discretionary), yang tidak secara langsung dan eksplisit mendapat penghargaan dari sistem imbalan formal, dan yang secara keseluruhan mendorong keefektifan fungsi-fungsi organisasi. Bersifat bebas dan sukarela, karena perilaku tersebut tidak diharuskan oleh persyaratan peran atau deskripsi jabatan, yang secara jelas dituntut berdasarkan kontrak dengan organisasi; melainkan sebagai pilihan personal

Menurut McKenzie \& Podsakoff (1998), OCB dapat mempengaruhi keefektifan organisasi karena beberapa alasan. Pertama, OCB dapat membantu meningkatkan produktivitas rekan kerja. Kedua, OCB dapat membantu meningkatkan produktivitas manajerial. Ketiga, OCB dapat membantu mengefisienkan penggunaan sumberdaya organisasional untuk tujuan-tujuan produktif. Keempat, OCB dapat menurunkan tingkat kebutuhan akan penyediaan sumberdaya organisasional untuk tujuan-tujuan pemeliharaan karyawan. Kelima, OCB dapat dijadikan sebagai dasar yang efektif untuk aktivitas-aktivitas koordinasi antara anggota-anggota tim dan antar kelompok-kelompok kerja. Keenam, OCB dapat meningkatkan kemampuan organisasi untuk mendapatkan dan mempertahankan SDM-SDM handal dengan memberikan kesan bahwa organisasi merupakan tempat bekerja yang lebih menarik. Ketujuh, OCB dapat meningkatkan stabilitas kinerja organisasi. Alasan terakhir adalah OCB dapat meningkatkan kemampuan organisasi untuk beradaptasi terhadap perubahan-perubahan lingkungan bisnisnya. 
Istilah Organizational Citizenship Behavior (OCB) pertama kali diajukan oleh Organ yang mengemukakan lima dimensi primer dari OCB (Allen \& Rush, 1998), yaitu Altruism, Civic Virtue, Conscinetiousness, Courtesy dan Sportmanship. Altruism merupakan perilaku membantu karyawan lain tanpa ada paksaan pada tugas-tugas yang berkaitan erat dengan operasi-operasi organisasional. Civic Virtue menunjukkan partisipasi sukarela dan dukungan terhadap fungsi-fungsi organisasi baik secara professional maupun social alamiah. Conscinetiousness berisi tentang kinerja dari prasyarat peran yang melebihi standar minimum. Courtesy adalah perilaku meringankan problem-problem yang berkaitan dengan pekerjaan yang dihadapi orang lain. Sportmanship, berisi tentang pantangan-pantangan membuat isu yang merusak meskipun merasa jengkel.

\subsection{Behavior Intention}

Pemahaman terhadap perilaku konsumen akan memudahkan manajemen dalam upaya untuk mengembangkan produk atau jasanya sesuai kebutuhan dan keinginan konsumen. Keinginan berperilaku konsumen seringkali didasarkan pada kemungkinan tindakan yang akan dilakukan. Niat berperilaku (behavioral intentions) merupakan keinginan konsumen untuk berperilaku menurut cara tertentu dalam rangka memiliki, membuang, dan menggunakan produk atau jasa. Jadi konsumen dapat membentuk keinginan untuk mencari informasi, memberitahukan orang lain tentang pengalamannya dengan sebuah produk, membeli sebuah produk atau jasa tertentu, atau membuang produk dengan cara tertentu.

Pengukuran niat berperilaku dapat menjadi cara terbaik untuk memprediksikan perilaku pembelian yang akan datang. Pendapat ini ditegaskan oleh Parasuraman, et al. (1991) yang mengatakan, "[k]onsekuensi yang timbul dari persepsi terhadap kualitas jasa dalam bentuk niat berperilaku konsumen individual dapat dipandang sebagai sinyal keberhasilan atau kegagalan perusahaan untuk mempertahankan konsumennya."

\subsection{KERANGKA PEMIKIRAN}

Pada kerangka pemikiran tersebut terdapat sebuah variabel independen sebagai observed variable (variabel yang diamati) yakni Organizational Citizenship Behavior (OCB) untuk diteliti dan dianalisis lebih lanjut bagaimana pengaruhnya pada Service Quality, Satisfaction dan Behavioral Intention yang berfungsi sebagai variabel anteseden serta bagaimana pengaruhnya pada Performance sebagai variabel dependen secara langsung maupun tidak langsung (melalui Service Quality, Satisfaction dan Behavioral Intention). 


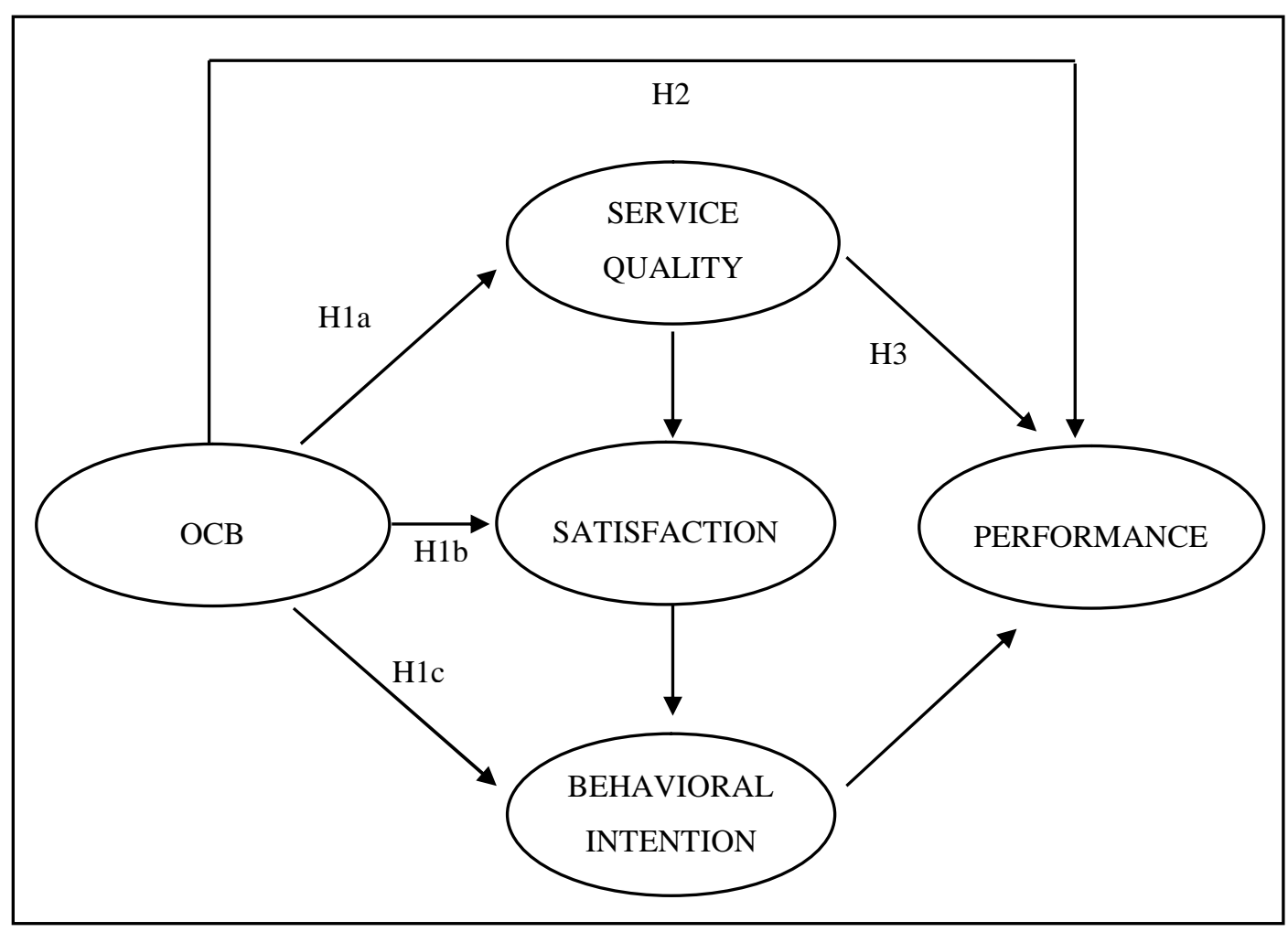

Gambar 1. Kerangka Pemikiran

\subsection{HIPOTESIS PENELITIAN}

\subsubsection{OCB dan Service Quality}

Ada dua argumen utama dalam mendukung hubungan positif antara OCB dan persepsi konsumen pada service quality. Pertama, OCB dapat memiliki efek langsung yang berasal dari interaksi antara karyawan dan konsumen. Kedua, efek yang lebih positif dapat terjadi melalui faktor internal organisasi seperti lingkungan kerja, climate service dan konsistensi proses pelayanan. Lebih dari itu, sudut pandang ini menyediakan suatu perbedaaan konsep OCB dilihat dari orientasi pasar (Bell \& Menguc, 2002).

OCB memberikan kontribusi baik secara langsung maupun tidak langsung dalam menciptakan persepsi yang unggul dalam service quality (Morrison, 1996). Memang, perilaku ini telah digambarkan oleh literatur mengenai service sebagai hal penting untuk mencapai keuntungan lebih. Sangatlah penting jika karyawan berperilaku tepat sesuai dengan peran mereka jika tingkat kualitas yang harus dicapai lebih tinggi. Karyawan menampilkan perilaku yang mewakili OCB mampu memberikan service quality karena mereka berusaha untuk membantu konsumen dengan hal terbaik.

Teori sosialisasi juga memberikan kontribusi pemahaman tentang hubungan ini. Proses sosialisasi individu dalam suatu organisasi mendorong dimensi OCB menjadi perilaku yang ditujuan untuk mencapai hasil yang lebih baik bagi konsumen (Netemeyer, Boles, Mckee \& McMurrian, 1997). OCB dianggap sebagai refleksi dari 
komitmen karyawan komitmen terhadap organisasi mereka. Jadi, Kelley (1992) mengidentifikasi asosiasi antara proses sosialisasi, afektif dan perilaku orientasi karyawan. Kelley (1992) mempertimbangkan proses ini menjadi aspek penting dalam keterlibatan karyawan dengan organisasinya. Oleh karena itu, jika seorang karyawan merasakan bahwa lingkungan kerja organisasi positif, dan jika tingkat karyawan komitmen serta keterlibatannya tinggi, karyawan lebih cenderung berorientasi konsumen (Williams \& Sanchez dalam Castro \& David, 2004). Efek ini disebut "service climate" (Schneider \& Bowen dalam Castro \& David, 2004). Persepsi karyawan pada "service climate" tidak hanya memiliki dampak signifikan pada variabel organisasi seperti kepuasan kerja dan motivasi, tetapi juga secara langsung mempengaruhi penilaian konsumen servis yang diberikan (Yoon dalam Castro \& David, 2004). Orientasi konsumen yang lebih tinggi meningkatkan persepsi konsumen terhadap pelayanan yang diberikan oleh organisasi. Selain itu, umpan balik positif konsumen akan memperkuat orientasi konsumen dari karyawan. Karena itu, diharapkan bahwa hubungan yang ada antara OCB (sebagai akibat positif dari sosialisasi karyawan) dan persepsi service quality.

Manfaat kedua dari aspek OCB internal dari organisasi. OCB mendorong kerjasama tim, mengkomunikasikan antara karyawan dan manajemen, memperbaiki lingkungan kerja, dan mengurangi tingkat pembelotan karyawan. Disimpulkan, "good soldiers" dapat membantu karyawan lain untuk memberikan layanan yang berkualitas, karena mereka adalah calon yang cocok untuk memulai quality progam dalam organisasi (Hui et al. dalam Castro \& David, 2004).

\section{H1a : OCB berpengaruh positif terhadap persepsi konsumen pada service quality}

\subsubsection{OCB dan Consumer Satisfaction}

Alasan yang sama dapat dikatakan untuk menjelaskan hubungan antara OCB dan kepuasan konsumen. Penelitian sebelumnya mengenai teori sosialisasi, dan service climate development (Schneider \& Bowen, 1999) mendukung pernyataan ini. Secara khusus, konsumen menilai layanan tergantung pada kompetensi, sikap, keahlian, dan keterampilan dari interaksi antara konsumen dan karyawan. Oleh karena itu, interaksi antara konsumen dengan perilaku karyawan sangat berpengaruh dalam hubungan pelayanan (Paulin et.al dalam Castro \& David, 2004). Sehingga, sangatlah penting untuk mengembangkan hubungan internal, tidak hanya di kalangan karyawan, tetapi juga antara karyawan dengan organisasi sebelum menciptakan dan meningkatkan hubungan yang sukses dengan konsumen. Dengan kata lain hanya jika hubungan karyawan terjadi, hubungan layanan dengan konsumen baru akan berhasil (Kelley \& Hoffman, 1997). Dalam hal ini, peran ekstra OCB merupakan faktor penting yang mempengaruhi service quality dan consumer satisfaction (Yoon \& Suh dalam Castro \& David, 2004). Demikian pula, Bitner et al. (1994) menunjukkan bahwa kepuasan konsumen sangat dipengaruhi oleh proses interaksi antara konsumen dengan karyawan pribadi. 


\section{H1b : $O C B$ berpengaruh positif terhadap consumer satisfaction}

\subsubsection{OCB dan Intention Behavior Konsumen}

Hansen et al. (2003) mengatakan bahwa komitmen konsumen terhadap layanan organisasi secara signifikan bergantung pada komitmen konsumen terhadap konsumen dengan karyawan. Jadi, niat konsumen untuk tetap dengan organisasi jasa tertentu sangat ditentukan oleh hubungan antara konsumen dengan perilaku karyawan. Berdasarkan penelitian sebelumnya dalam teori social network (GraNoveter, 1973), dapat dinyatakan bahwa ketika seorang konsumen puas dengan pelayanan karyawan dalam lingkup hubungan formal, konsumen akan mungkin mempertahankan hubungan dalam jangka panjang (Hansen et al., 2003). Bahkan OCB memungkinkan konsumen untuk lebih berkomitmen pada hubungan konsumen dengan karyawan. Oleh karena itu, sangat penting bagi organisasi untuk mendorong perilaku discretional sukarela ini, karena mereka meningkatkan hubungan antara karyawan dan juga hubungan antara karyawan dan konsumen (Yoon \& Suh, 2003). Peningkatan hubungan meningkatkan tingkat komitmen konsumen terhadap organisasi (melalui hubungan karyawan organisasi) dan mereka bermaksud untuk tetap menjadi konsumen.

\section{H1c : OCB berpengaruh positif terhadap intention behavior konsumen}

\subsection{OCB dan Kinerja Organisasi}

Meskipun kebanyakan studi telah meneliti pendahulu dari OCB, ada juga beberapa studi yang telah menganalisis konsekuensi-konsekuensinya. Studi-studi ini dapat diklasifikasikan ke dalam dua kelompok (Podsakoff et al., 2000), yaitu yang menjelajahi pengaruh OCB terhadap penilaian manajerial karyawan dan yang menghubungkan OCB dengan kinerja organisasi dan keberhasilan.

Organ (1988) menyimpulkan sebuah temuan bahwa kinerja organisasi meningkatkan ketika perilaku "extra role" tetap dari waktu ke waktu dalam sejumlah besar karyawan. Asumsi ini telah diterima dari perspektif teoretis, meskipun tanpa banyak bukti empiris (McKenzie \& Podsakoff, 1994). Dari perspektif konseptual, ada banyak argumen yang mendukung hipotesis ini: Dari perspektif empiris, hubungan ini kurang mendapat perhatian (McKenzie \& Podsakoff, 1994). Namun demikian, bukti dari studi ini mendukung hipotesis bahwa OCB membantu untuk mencapai hasil yang lebih baik secara kualitatif dan kuantitatif. McKenzie \& Podsakoff (1994) menunjukkan bahwa OCB meningkatkan organisasi efektivitas, karena memiliki kemampuan untuk menarik dan mempertahankan karyawan terbaik dengan iklim layanan menarik.

Selain itu, OCB juga memungkinkan stabilitas dalam hal kinerja organisasi (tingkat output tinggi). Namun, beberapa jenis perilaku mungkin lebih signifikan dalam menganalisis hubungan antara perilaku individu dan kinerja organisasi. OCB membantu 
organisasi untuk beradaptasi terhadap perubahan lingkungan. Dari uraian di atas, hipotesis berikut diusulkan:

\section{H2: OCB berpengaruh positif terhadap kinerja organisasi.}

\subsubsection{Service Quality dan Kinerja Organisasi}

Hubungan antara keinginan konsumen dan keuntungan organisasi telah dijabarkan secara luas. Reichheld \& Sasser (dalam Castro \& David, 2004) menyatakan bahwa peran konsumen sangat penting dalam kinerja organisasi. Selain itu, Sheth \& Parvatiyar (dalam Castro \& David, 2004) mengusulkan bahwa biaya mempertahankan konsumen sering jauh lebih rendah daripada biaya mendapatkan konsumen baru. Dalam hal yang sama, Reichheld (dalam Castro \& David, 2004) menyimpulkan bahwa keuntungan secara ekonomi dari loyalitas konsumen sangat penting dalam faktor ini, apa yang dimiliki menjelaskan perbedaan kinerja antara organisasi-organisasi di banyak industri. Selanjutnya, Reichheld mencatat bahwa kinerja organisasi meningkatkan kemungkinan organisasi untuk berinvestasi lebih banyak pada sumber daya dalam memotivasi dan meningkatkan hubungan dengan karyawan organisasinya untuk memastikan keinginan konsumen.

Oleh karena itu, keberadaan variabel intermediate (selain kepuasan dan loyalitas) antara kualitas dan keuntungan harus diperhitungkan, bersama-sama dengan observasi bahwa antara variabel-variabel ini banyak mempengaruhi. Korelasi antara kualitas dan keuntungan tergantung pada lingkup yang luas dari faktor-faktor organisasi (Hardie dalam Castro \& David, 2004). Lebih lanjut, penelitian ini, bertujuan melakukan penelitian secara mendalam tentang hubungan antara variabel-variabel (Zeithmal dalam Pasuraman, 1991).

\section{H3: service quality berhubungan positif dengan organizational performance}

\section{METODE PENELITIAN}

\subsection{Desain Penelitian}

Penelitian ini merupakan Descriptive dan Explanatory Research. Menurut Jogiyanto (2004), descriptive research merupakan riset yang bertujuan untuk menggambarkan suatu peristiwa, siapa yang terlibat, apa yang dilakukan, kapan dilakukan, di mana dan bagaimana melakukannya. Adapun explanatory research merupakan riset yang mencoba menjelaskan fenomena yang ada.

Dilihat dari dimensi waktunya, penelitian ini adalah penelitian cross-sectional. Jogiyanto (2004) mengemukakan bahwa penelitian cross-sectional melibatkan satu waktu tertentu dengan banyak sampel. Berdasarkan setting-nya, penelitian ini melibatkan lingkungan non contrived setting, yaitu lingkungan riil (field setting). Unit analisis dalam 
penelitian ini adalah individual, di mana individu responden akan diminta tanggapannya mengenai variabel-variabel yang diteliti.

\subsection{Jenis Data}

Data yang dibutuhkan dalam penelitian ini meliputi data primer dan sekunder. Data primer diperoleh dari responden penelitian melalui kuesioner sebagai alat pengumpulan data. Data yang dikumpulkan mencakup profil responden serta tanggapan responden mengenai variabel-variabel yang diteliti. Sedangkan data sekunder dalam penelitian ini meliputi data-data dokumentasi yang terkait dengan obyek penelitian, seperti profil organisasi, deskripsi SDM, dan data-data lain yang dibutuhkan.

\subsection{Definisi Operasional Variabel}

Variabel-variabel yang digunakan dalam penelitian ini meliputi Organizational Citizenship Behavior (OCB), Service Quality, Satisfaction, Behavior Intention dan Performance. Variabel Organizational Citizenship Behavior (OCB) diukur menggunakan 16 pertanyaan yang diadaptasi dari Castro \& David (2004). Variabel service quality diukur menggunakan 22 pertanyaan yang diadaptasi dari Castro \& David (2004). Variabel satisfaction diukur menggunakan 9 pertanyaan dari Castro \& David (2004). Variabel behavior intention diukur menggunakan 8 pertanyaan dari Castro \& David (2004). Akhirnya, variabel performance diukur menggunakan 9 pertanyaan dari Becker, Billings, Eveleth \& Gilbert (1996).

\subsection{Populasi, Sampel dan Teknik Sampling}

Populasi dalam penelitian ini adalah adalah perawat sebuah rumah sakit swasta di Surakarta, Jawa Tengah. Penelitian ini menggunakan model persamaan struktural (Structural Equation Modelling/SEM), maka menurut Hair, Jr., Anderson, Tathan \& Black (2006), jumlah sampel yang diperlukan untuk pengujian model dengan menggunakan SEM adalah berkisar 100-200 atau ukuran sampel minimal lima kali observasi untuk estimated parameter. Teknik Sampling dalam penelitian ini menggunakan metode convenience sampling. Convenience sampling merupakan pengumpulan informasi dari anggota populasi yang dengan senang hati bersedia memberikannya (Sekaran, 2003).

\subsection{Pengujian Instrumen Penelitian}

Uji validitas digunakan untuk mengukur apakah instrumen penelitian benar-benar mampu mengukur konstruk yang digunakan. Untuk uji validitas digunakan alat uji Confirmatory Factor Analysis dengan bantuan Amos FOR WINDOWS versi 18.00.

Uji reliabilitas dimaksudkan untuk mengetahui tingkat konsistensi terhadap instrumen-instrumen yang mengukur konsep. Untuk menguji realibilitas digunakan alat 
ukur dengan teknik Cronbach Alpha dengan bantuan SPSS FOR WINDOWS versi 16. Nilai Cronbach Alpha dapat dikatakan reliable (andal) apabila nilainya > 0,6.

\subsection{Metode Analisis Data}

Metode analisis yang digunakan dalam penelitian ini menggunakan Structural Equation Modelling (SEM). SEM merupakan teknik multivariate yang mengkombinasikan aspek regresi berganda dan analisis faktor untuk mengestimasi serangkaian hubungan ketergantungan secara simultan (Hair et al., 2006). Pengujian hipotesis dilakukan dengan menggunakan program Amos versi 18.00 untuk menganalisis hubungan kausalitas dalam model struktural yang diusulkan.

\section{TEMUAN DAN PEMBAHASAN}

\subsection{Uji Instrumen Penelitian (Measurement Model)}

\subsubsection{Uji Validitas}

Pedoman umum untuk analisis faktor adalah output rotated component matrix yang terekstrak sempurna (Ghozali, 2005:50). Berdasarkan uji validitas dengan bantuan program SPSS 16.00, empat item pertanyaan tidak diikutsertakan dalam analisis karena tidak terekstrak secara sempurna, sedangkan item-item yang lain dinyatakan valid.

\subsubsection{Uji Reliabilitas}

Teknik pengujian yang digunakan adalah teknik alpha cronbach. Sekaran (2003:203) mengklasifikasi nilai cronbach's alpha, sebagai berikut. Koefisien antara 0.80-1.00 menunjukkan reliabilitas yang baik. Koefisien antara 0.60-0.79 menunjukkan reliabilitas masih dapat diterima. Akhirnya, koefisien $<0.60$ menunjukkan reliabilitas yang kurang baik.

Tabel 1. Hasil Uji Reliabilitas Variabel

\begin{tabular}{lccc}
\hline \multirow{2}{*}{ Variabel } & Instrumen & $\begin{array}{c}\text { Cronbach's } \\
\text { Alpha }\end{array}$ & Keterangan \\
\hline \multirow{3}{*}{ OCB } & SP & 0,908 & Baik \\
& CV & 0,704 & Dapat Diterima \\
& C & 0,652 & Dapa Diterima \\
& AL & 0,303 & Buruk \\
\multirow{3}{*}{ Service Quality } & T & 0,862 & Baik \\
& RL & 0,860 & Baik \\
& RP & 0,812 & Baik \\
Satisfaction & $\mathrm{A}$ & 0,852 & Baik \\
\hline \multirow{2}{*}{ Behavioural Intention } & $\mathrm{E}$ & 0,533 & Buruk \\
\hline Performance & $\mathrm{S}$ & 0,771 & Dapat Diterima \\
\hline
\end{tabular}


Dari hasil pengujian reliabilitas variabel dengan menggunakan bantuan program SPSS 16.00 sehingga didapatkan nilai Cronbach's alpha masing-masing variabel seperti dijabarkan pada Tabel 1. Dari Tabel 1 dapat diketahui bahwa variabel instrumen SP, T, RL, RP, A dan P mempunyai reliabilitas yang baik karena koefisien cronbach's alphanya lebih dari 0,80 yakni $\mathrm{SP}(0,908), \mathrm{T}(0,862), \operatorname{RL}(0,860), \operatorname{RP}(0,812)$ dan $\mathrm{P}(0,901)$. Untuk variabel CV, C, S, SC dan LY mempunyai reliabilitas yang dapat diterima karena nilai cronbach's alpha-nya ada diantara 0,60 sampai 0,79 yakni $\mathrm{CV}(0,704), \mathrm{C}(0,652)$, $\mathrm{S}(0,771), \mathrm{SC}(0,770)$ dan LY(0,726). Sedangkan untuk variabel instrumen AL dan E mempunyai realibilitas yang kurang baik karena nilai cronbach's alpha-nya kurang dari 0.6 yakni AL (303) dan E (0,533).

\subsection{Karakteristik Data}

Sebelum pengujian kesesuaian model dan hipotesis dalam penelitian ini, terlebih dahulu akan dilihat karakteristik data yang akan digunakan dalam analisis ini. Pengujian terhadap karakteristik data yang dimaksud, meliputi : normalitas data, evaluasi outliers dan uji hipotesis.

\subsubsection{Normalitas Data}

Apabila asumsi normalitas tidak dipenuhi dan penyimpangan normalitas tersebut besar, maka akan mengakibatkan hasil uji statistik yang bias. Untuk menguji asumsi normalitas dengan membandingkan nilai critical ratio skewness dan kurtosis dengan nilai kritis pada tingkat signifikansi tertentu. Rules of thumb yang digunakan adalah apabila nilai critical ratio skewness dan kurtosis lebih dari \pm 2.58 pada tingkat 0.01 berarti distribusi data tidak normal. Di samping itu, Curran et.al. (dalam Ghozali, 2005) membagi distribusi data menjadi tiga bagian, yaitu: normal distribution, moderately nonnormal dan Extremely non-normal. Apabila nilai z statistik (critical ratio atau C.r.) skewness $<2$ dan nilai C.r. kurtosis $<7$, distribusi data yang terbentuk normal. Apabila nilai C.r. skewness berkisar antara 2-3 dan nilai C.r. kurtosis berkisar antara 7-21, distribusi data yang terbentuk dikatakan Moderately non-normal. Akhirnya, apabila nilai C.r. skewness $>3$ dan nilai C.r. kurtosis $>21$, distribusi data yang terbentuk dikatakan Extremely non-normal.

Evaluasi normalitas dapat diidentifikasi baik secara univariate maupun multivariate. Hasil evaluasi menunjukkan secara univariate untuk nilai-nilai dalam C.r. skewness, terdapat 3 instrumen pertanyaan yang memliki nilai C.r. skewness lebih dari 2.58. Kemudian, secara univariate untuk nilai-nilai dalam C.r kurtosis terdapat 4 instrumen yang memiliki nilai C.r. kurtosis lebih dari 2.58. Dengan demikian, dapat dikatakan bahwa data tidak terdistribusi normal secara univariate. Sementara secara multivariate, data dalam penelitian ini juga tidak terdistribusi normal karena nilai 6,775 lebih besar dari harga mutlak 2,58. 
Data yang tidak normal dapat mengakibatkan pembiasan intrepretasi karena nilai chi-square hasil analisis cenderung meningkat sehingga nilai probability level akan mengecil. Untuk data yang tidak normal secara multivariate, Ghozali (2005) menyarankan dengan menggunakan prosedur yang dikenal dengan "bootstrap". Namun, hal tersebut tidak perlu dilakukan karena nilai C.r. kurtosis multivariate masih kurang dari 21.00. Disamping itu, teknik Maximum Likelihood Estimates (MLE) yang digunakan dalam penelitian ini tidak terlalu terpengaruh (robust) terhadap data yang tidak normal (Ghozali, 2005) sehingga analisis selanjutnya masih dapat dilakukan.

\subsubsection{Evaluasi Outliers}

Identifikasi adanya multivariate outliers pada penelitian ini dilakukan dengan memperhatikan nilai mahalanobis distance (Ghozali, 2005). Kriteria yang digunakan adalah berdasarkan nilai chi-square pada derajat bebas (degree of freedom) 50 yaitu jumlah variabel indikator pada tingkat signifikansi $\mathrm{p}<0.001$. Dalam penelitian ini setelah menggunakan uji validitas maka indikator yang awalnya 55 item telah disederhanakan sehingga menjadi 50 item saja. Kriteria yang digunakan adalah berdasarkan nilai Chi Squares pada derajat kebebasan (degree of freedom) 50. Oleh karena itu, nilai mahalanobis distance $(50,0.001)=86,662$. Hal ini berarti semua kasus yang mempunyai mahalanobis distance yang lebih besar dari 88,6660 akan dikategorikan sebagai multivariate outliers. Berdasarkan evaluasi outlier, diketahui tidak ada outliers atau responden yang memiliki nilai mahalanobis distance yang lebih besar dari 86,66260.

\subsection{Kesesuaian Goodness of Fit}

Sebelum melakukan teknik pengujian hipotesis, langkah yang pertama adalah menilai kesesuaian goodness of fit. Kriteria penilaian untuk goodness of fit pada model tertera pada Tabel 2. Pada Tabel 2 dapat dilihat bahwa chi-square yang bernilai 131.393 adalah signifikan secara statistik pada level signifikansi 0,01. Probabilitas sebesar 0.01 lebih kecil dari 0.05 hal ini merupakan indikasi yang sangat buruk. Dengan demikian, terdapat perbedaan antara matrik kovarian sampel dengan matrik kovarian populasi yang diamati. Nilai GFI sebesar 0.873 merupakan indikasi yang marginal. Nilai RMSEA sebesar 0.069 merupakan indikasi yang baik. Sementara dari indeks incremental fit measures didapat nilai AGFI sebesar 0.819 merupakan indikasi yang marginal. Nilai TLI sebesar 0.916 merupakan indikasi yang baik. Kemudian, nilai CFI sebesar 0.933 merupakan indikasi yang baik. Nilai RMR adalah 0.022 merupakan indikasi yang baik. Sebagai tambahan dari indeks parsimony fit measures didapat nilai CMIN/df sebesar 1.564 merupakan indikasi baik karena mempunyai nilai kurang dari 5.00. Dari keseluruhan pengukuran goodness of fit tersebut di atas diindikasikan bahwa model dalam penelitian ini belum dapat diterima. Selain itu, nilai probabilitas juga belum memenuhi syarat. 
Tabel 2. Kriteria Goodness of Fit

\begin{tabular}{lccc}
\hline Goodness of Fit indeks & Nilai yang Diharapkan & Hasil & Evaluasi \\
\hline$X^{2}$ - Chi Square & Diharapkan rendah & 131.393 & Buruk \\
Probabilitas & $>0,05$ & 0.01 & Buruk \\
CMIN/df & $\leq 5$ & 1.564 & Baik \\
$R M R$ & Diharapkan rendah & 0.022 & Baik \\
GFI & $\geq 0,90$ & 0.873 & Marginal \\
AGFI & $\geq 0,90$ & 0.819 & Marginal \\
$T L I$ & $\geq 0,90$ & 0.916 & Baik \\
CFI & $\geq 0,90$ & 0.933 & Baik \\
RMSEA & $\leq 0,08$ & 0.069 & Baik \\
\hline
\end{tabular}

Oleh karena itu, peneliti mempertimbangkan untuk melakukan modifikasi model untuk membentuk model alternatif yang diharapkan memiliki goodness of fit yang lebih baik. Hal ini dilakukan dengan memperhatikan modification indices yang diperoleh dari hasil output analisis menggunakan AMOS 18.00.

\subsection{Modifikasi Model}

Mengingat hasil dari goodness of fit model belum diterima, maka peneliti mempertimbangkan untuk melakukan modifikasi model guna mendapatkan model yang fit. Hal tersebut dilakukan dengan memperhatikan nilai modification indices yang dapat mengetahui ada tidaknya kemungkinan modifikasi terhadap model yang dapat diusulkan. Modification indices dapat diketahui dari output AMOS 18.00 dimana akan ditunjukkan hubungan-hubungan yang perlu diestimasi agar terjadi penurunan nilai chi-square guna mendapatkan model penelitian yang lebih baik.

Tabel 3. Kriteria Goodness of Fit Sebelum dan Sesudah Modifikasi

\begin{tabular}{lccccc}
\hline $\begin{array}{c}\text { Goodness of Fit } \\
\text { indeks }\end{array}$ & $\begin{array}{c}\text { Nilai yang } \\
\text { Diharapkan }\end{array}$ & $\begin{array}{c}\text { Sebelum } \\
\text { Modifikasi }\end{array}$ & Evaluasi & $\begin{array}{c}\text { Sesudah } \\
\text { Modifikasi }\end{array}$ & Evaluasi \\
\hline$X^{2}$ - Chi Square & $\begin{array}{c}\text { Diharapkan } \\
\text { rendah }\end{array}$ & 131.393 & Buruk & 76.961 & Baik \\
Probabilitas & $>0,05$ & 0.00 & Buruk & 0.000 & Baik \\
CMIN/df & $\leq 5$ & 1.564 & Baik & 0.987 & Baik \\
& $\begin{array}{l}\text { Diharapkan } \\
\text { rendah }\end{array}$ & 0.022 & Baik & 0.019 & Baik \\
RMR & $\geq 0,90$ & 0.873 & Marginal & 0.924 & Baik \\
$G F I$ & $\geq 0,90$ & 0.819 & Marginal & 0.833 & Marginal \\
$A G F I$ & $\geq 0,90$ & 0.816 & Baik & 0.823 & Baik \\
$T L I$ & $\geq 0,90$ & 0.833 & Baik & 0.455 & Baik \\
$C F I$ & $\leq 0,08$ & 0.069 & Baik & 0.04 & Baik \\
$R M S E A$ & & & & & \\
\hline
\end{tabular}


Untuk mendapatkan kriteria model yang dapat diterima, peneliti mencoba mengestimasi hubungan korelasi antar error term yang tidak memerlukan justifikasi teoritis dan yang memiliki nilai modification indices lebih besar atau sama dengan 4,0. Dalam hal ini peneliti mengestimasi hubungan korelasi antar error term yakni e46<-$>\mathrm{e} 7$, e46<-->e65, e46<-->e47, e63<-->e7, e63<-->e65 dan e63<-->e47. Adapun hasil goodness of fit model yang telah dimodifikasi dapat dilihat pada Tabel 3.

Pada Tabel 3, setelah dimodifikasi maka terlihat adanya penurunan chi-square menjadi 76.961 adalah signifikan secara statistik pada level signifikansi 0.512. Evaluasi untuk nilai chi-square sebesar 76.961 adalah baik karena nilainya sudah mengalami penurunan cukup banyak. Untuk indeks goodness of fit lain sudah memenuhi kriteria yang ditentukan sehingga dari keseluruhan pengukuran tersebut diatas, diindikasikan bahwa model akhirnya dapat diterima dengan baik.

\subsection{Analisis Koefisien Jalur dan Uji Hipotesis}

Setelah uji goodness of fit model, maka tahap selanjutnya adalah menguji hipotesis. Tabel 4 berikut menunjukkan hipotesis dari model yang sudah dimodifikasi.

Tabel 4. Hasil Uji Hipotesis Setelah Modifikasi

\begin{tabular}{|c|c|c|c|c|c|c|c|c|}
\hline \multicolumn{4}{|c|}{ Hipotesis } & \multirow{2}{*}{$\frac{\text { Hubungan }}{+}$} & \multirow{2}{*}{$\begin{array}{r}\text { Estimate } \\
0.640\end{array}$} & \multirow{2}{*}{$\begin{array}{r}\text { S.E. } \\
0.301\end{array}$} & \multirow{2}{*}{$\frac{\text { C.R. }}{2.122}$} & \multirow{2}{*}{$\frac{\mathrm{P}}{0.034}$} \\
\hline H1a & SQ & $<---$ & OCB & & & & & \\
\hline $\mathrm{H} 1 \mathrm{~b}$ & $\mathrm{~S}$ & $<--$ & OCB & + & 0.034 & 0.073 & 0.468 & 0.640 \\
\hline $\mathrm{H} 1 \mathrm{c}$ & BI & $<--$ & OCB & - & 0.041 & 0.145 & 0.283 & 0.777 \\
\hline $\mathrm{H} 2$ & $\mathrm{P}$ & $<--$ & OCB & + & 0.668 & 0.185 & 3.600 & $* * *$ \\
\hline $\mathrm{H} 3$ & $\mathrm{P}$ & $<---$ & SQ & + & 0.713 & 0.187 & 3.816 & $* * *$ \\
\hline
\end{tabular}

Dari Tabel 4 dapat dilihat bahwa pengaruh Organizational Citizen Behaviourship pada service quality, Organizational Citizen Behaviourship pada performance dan service quality pada performance adalah signifikan pada probabilitas $P<0,05$ karena mempunyai nilai C.r lebih besar dari t tabel yaitu 1,96. Kemudian, pengaruh Organizational Citizen Behaviourship pada satisfaction dan Organizational Citizen Behaviourship pada behavioural intention tidak signifikan karena mempunyai nilai $\mathrm{C} . \mathrm{r}$ yang lebih kecil dari t tabel 1,96 dan $P>0,05$.

Adapun pembahasan untuk setiap hipotesis dalam penelitian ini adalah sebagai berikut:

\subsubsection{Hipotesis 1a}

H1a : OCB berpengaruh positif pada persepsi konsumen mengenai service quality

Berdasarkan hasil perhitungan pada tabel 4 dengan nilai C. $\mathrm{r}$ lebih dari 1.96 yakni sebesar 2.122 dengan signifikansi sebesar 0.034 pada $p<0.05$ maka dapat disimpulkan bahwa H1a didukung. Dengan kata lain, OCB mempengaruhi persepsi 
konsumen terhadap service quality. Secara khusus, pasien rumah sakit menilai pelayanan rumah sakit tergantung pada kompetensi, sikap, keahlian, dan keterampilan dari interaksi antara pasien dan perawat. Oleh karena itu, interaksi antara konsumen dengan perilaku karyawan sangat berpengaruh dalam hubungan pelayanan (Paulin et.al dalam Castro \& David, 2004). Sehingga, sangatlah penting untuk mengembangkan hubungan internal, tidak hanya di kalangan perawat, tetapi juga antara perawat dengan pihak manajemen itu sendiri sebelum menciptakan dan meningkatkan hubungan yang sukses dengan para pasiennya. Dengan kata lain hanya jika hubungan karyawan terjadi, hubungan layanan dengan konsumen baru akan berhasil (Kelley \& Hoffman, 1997). Hal ini sejalan dengan hasil penelitian Castro \& David (2004).

\subsubsection{Hipotesis $1 \mathrm{~b}$}

\section{$\mathrm{H} 1 \mathrm{~b}: O C B$ berpengaruh positif pada consumer satisfaction}

Berdasarkan hasil perhitungan pada tabel 4 dengan nilai C. $\mathrm{r}$ kurang dari 1.96 yakni sebesar 0.468 , tidak signifikan pada $p<0.05$ karena signifikansinya 0.640 maka dapat disimpulkan bahwa H1b tidak didukung. Dengan kata lain, OCB tidak mempengaruhi customer satisfaction. Artinya kepuasan pasien terhadap pelayanan rumah sakit tidak dipengaruhi oleh hubungan mereka dengan para perawatnya. Hal ini dimungkinkan karena kepuasan pasien lebih dipengaruhi oleh service quality yang diberikan rumah sakit secara langsung. Bukan karena subyek yang menjadi perantaranya yaitu perawat. Misalnya saja dalam segi pembiayaan dan fasilitas, kebijakan condong rumah sakit ini lebih mempermudah dalam hal pembiayaan serta fasilitas dibanding rumah sakit lain yang lebih unggul. Pasien di kelas 3 rumah sakit ini mendapat pelayanan lebih baik dibandingkan rumah sakit lain. Hasil penelitian ini tidak sejalan dengan hasil penelitian Castro \& David (2004).

\subsubsection{Hipotesis $1 \mathrm{c}$}

H1c : OCB berpengaruh positif pada intention behavior konsumen

Berdasarkan hasil perhitungan pada tabel 4 dengan nilai C. $\mathrm{r}$ kurang dari 1.96 yakni sebesar 0.283 serta tidak signifikan pada $p<0.05$ karena signifikansinya 0.777 , maka dapat disimpulkan bahwa H1c tidak didukung. Dengan kata lain, OCB tidak mempengaruhi intention behaviour pasien pada rumah sakit ini. Artinya OCB belum tentu memungkinkan konsumen untuk lebih berkomitmen pada hubungan konsumen dengan karyawan. Bisa dikatakan OCB yang dilakukan oleh perawat rumah sakit ini kurang didorong oleh organisasi. Padahal sangat penting bagi organisasi untuk mendorong perilaku discretional sukarela ini, karena mereka meningkatkan hubungan antara perawat dan juga hubungan antara perawat dan pasien (Yoon \& Suh, 2003). Karena peningkatan hubungan dapat mempengaruhi tingkat komitmen pasien terhadap rumah sakit (melalui hubungan dengan perawat) sehingga mereka akan tetap menjadi pelanggan rumah sakit ini. Hal ini bisa diatasi dengan pemberian insentif kepada 
karyawan jika memungkinkan untuk dilakukan. Hasil ini berbeda dengan hasil penelitian yang dilakukan oleh Castro \& David (2004).

\subsubsection{Hipotesis 2}

H2 : OCB berpengaruh positif pada kinerja organisasi.

Berdasarkan hasil perhitungan pada tabel 4 dengan nilai C.r lebih dari 1.96 yakni 3.600, signifikan pada $p<0.05$, maka dapat disimpulkan bahwa $\boldsymbol{H} 2$ didukung. Dengan kata lain, kinerja rumah sakit dipengaruhi oleh OCB perawat. Artinya menurut para supervisor di rumah sakit ini, perawat dalam melakukan pekerjaan mereka yang "extra role" memungkinkan stabilitas dalam meningkatkan kinerja rumah sakit itu sendiri. Hasil ini berbeda dengan hasil penelitian Castro \& David (2004).

\subsubsection{Hipotesis 3}

H3 : Service quality berpengaruh positif pada organizational performance

Berdasarkan hasil perhitungan pada tabel 4 dengan nilai C.r lebih dari 1.96 yakni 3.816, signifikan pada $p<0.05$, maka dapat disimpulkan bahwa $\boldsymbol{H 3}$ didukung. Dengan kata lain, organizational performance dipengaruhi oleh service quality. Artinya kualitas pelayanan terhadap konsumen sangat penting bagi kinerja organisasi. Selain itu, biaya mempertahankan pasien sering jauh lebih rendah daripada biaya mendapatkan pasien baru (Sheth \& Parvatiyar dalam Castro \& David, 2004). Di samping itu, keuntungan secara ekonomi dari loyalitas pasien juga sangat penting. Selanjutnya, kinerja organisasi meningkatkan kemungkinan rumah sakit untuk berinvestasi lebih banyak pada sumber daya dalam memotivasi dan meningkatkan hubungan dengan perawat untuk memastikan keinginan pasien. Hasil ini sejalan dengan hasil penelitian Castro \& David (2004).

\section{KESIMPULAN}

Dari hasil penelitian dengan menggunakan metode analisis Structural Equation Modelling (SEM) maka dapat diambil simpulan bahwa OCB berpengaruh positif pada persepsi konsumen mengenai service quality. Kedua, OCB tidak berpengaruh pada consumer satisfaction. Ketiga, OCB tidak berpengaruh pada intention behavior konsumen. Keempat, OCB berpengaruh positif pada kinerja organisasi. Terakhir, Service quality berpengaruh positif pada organizational performance.

Objek amatan yang digunakan dalam studi ini difokuskan pada $O C B$ dan performance sehingga berdampak pada generalisasi studi yang bersifat terbatas. Untuk mengaplikasi studi ini pada konteks yang berbeda, diperlukan kehati-hatian untuk mencermati jenis karakteristik variabel pada obyek yang dipelajari. Hal ini diperlukan agar tidak terjadi pembiasan hasil-hasil pengujian yang dapat berdampak pada kekeliruan dalam merumuskan kebijakan yang diambil. 
Hasil penelitian ini hanya didasarkan pada jawaban para responden melalui kuesioner dan tidak didukung adanya hasil wawancara secara mendetail dengan para karyawan, sehingga data yang dikumpulkan mungkin tidak mampu menggambarkan keadaan yang sebenarnya.

Dalam penelitian ini juga tidak dilakukan pretest dalam penyebaran kuesioner. Hal ini menyebabkan adanya beberapa indikator yang harus dikeluarkan dari analisis karena mempunyai factor loading yang rendah.

Saran yang diberikan terbagi menjadi saran akademis dan saran praktis. Pertama, dilihat dari saran dalam hal akademis ialah ruang lingkup responden yang diambil pada sebuah rumah sakit swasta di Surakarta, Jawa Tengah. Keterbatasan ini mengisyaratkan perlunya studi-studi lanjutan untuk menggeneralisasi hasil-hasil yang diperoleh pada konteks yang berbeda dan lebih luas, sehingga konsep-konsep yang diuji dalam model dapat ditingkatkan validitas eksternalnya. Saran akademis kedua ialah perlunya dilakukan pretest pada awal penelitian, sehingga jika ada item pertanyaan yang tidak valid, item tersebut dapat diperbaiki terlebih dahulu, tanpa harus dikeluarkan secara langsung dari analisis. Yang ketiga, hasil pengujian yang diperoleh diharapkan dapat digunakan sebagai acuan di bidang studi manajemen sumber daya manusia terutama OCB dan performance sebab konsep-konsep yang dikonstruksi ada yang mendukung serta menolak model yang telah dikemukakan oleh studi-studi terdahulu.

Hasil penelitian ini diharapkan dapat memberikan pemahaman kepada pihak rumah sakit agar dapat menjadi pedoman untuk meningkatkan peran $O C B$ terhadap organizational performance. Terdapat dua saran praktis yang dapat diterapkan. Implikasi manajerial dapat dilakukan ialah pertama, mengacu pada hasil analisis pengaruh $O C B$ pada consumer satisfaction. Berdasarkan indikator-indikator pada kuesioner, sebaiknya pihak rumah sakit melakukan langkah-langkah berupa lebih memenuhi kebutuhan pasien dan memberikan fasilitas serta pelayanan yang lebih unggul agar pasien merasa puas. Kemudian memberi kepercayaan kepada pasien bahwa rumah sakit ini mampu untuk diandalkan. Terakhir, memberikan perbandingan kualitas layanan antara rumah sakit ini dengan rumah sakit lain sehingga pasien tahu apa yang menjadi keunggulan rumah sakit ini dibanding rumah sakit yang lain.

Saran praktis yang kedua mengacu pada hasil analisis mengenai pengaruh OCB terhadap intention behavior konsumen. Berdasarkan indikator-indikator pada kuesioner, sebaiknya pihak rumah sakit melakukan langkah-langkah, yakni sebaiknya rumah sakit lebih hati-hati dalam penerapan biaya pelayanan rumah sakit. Karena pasien cenderung lebih menyukai rumah sakit dimana biaya pelayanannya lebih murah. Atau paling tidak, jika biaya memang sudah tidak bisa diubah lagi dalam artian diturunkan paling tidak rumah sakit memberikan pelayanan yang berbeda (lebih unggul) dibandingkan denga rumah sakit lain. Kemudian, menyakinkan pasien bahwa rumah sakit ini menjadi pilihan utama dalam pemenuhan layanan kesehatan. Selanjutnya, perawat lebih membantu perawat baru dalam menjalankan tugasnya. Selain itu, perawat juga harus lebih 
meluangkan waktu untuk perawat yang lain. Terakhir, perawat sebaiknya lebih cepat menanggapi permintaan para pasiennya.

\section{DAFTAR PUSTAKA}

Allen, T. D., \& Rush, M. C. (1998). The effects of organizational citizenship behavior on performance judgements: A field study and a laboratory experiment. Journal of Applied Psychology, 83, 247 - 260

Babin, B. J., \& Boles, J. S. (1998). Employee behaviour in a service environment: A model and test of potential differences between men and women. Journal of Marketing, 62, 77-91.

Becker, T. E., Billings, R. S., Eveleth, D. M., \& Gilbert, N. L. (1996). Foci and bases of employee commitment: implication for job performance. Academy of Management Journal, 39, 464-482.

Bell, S., \& Menguc, B. (2002). The employee-organization relationship, organizational citizenship behaviours and superior service qualit. Journal of Retailing, 78, $131-46$.

Berry, L. (1995). Relationships marketing of services, growing interest, emerging perspectives. Journal of Academy of Marketing Science, 23 (4), 236-45.

Boulding, W., Kalra, A., Staelin, R., \& Zeithaml, V. (1993). A dynamic process model of service quality: from expectations to behavioral intentions. Journal of Marketing Research, 30, 7-27.

Brown, S. P., \& Peterson, R. A. (1993). The effect of effort on sales performance and job satisfaction. Journal of Marketing, 58, 70-80.

Castro, M. \& David M. R. (2004). The influence of employee organizational citizenship behavior on customer loyalty. International Journal of Service Industry Management, 15, 27-53

Ghozali, I. (2005). Model persamaan struktural : Konsep dan aplikasi dengan program AMOS Ver. 16.0. Semarang : BP UNDIP

Ghozali, I. (2006). Analisis multivariate menggunakan SPSS 12.00. Semarang: BP UNDIP

Gibson, J. M., \& Ivancevich, J. M. (1997). Manajemen. Jakarta : Erlangga.

Gronroos, C. (1990). A relationships approach to marketing: the need for a new paradigm. Working Paper 190. Helsinki : Swedish School of Economics 
Gwinner, K. P., Gremler, D., \& Bitner, M. J. (1998). Relational benefits in services industries : theconsumer's perspective. Journal of the Academy of Marketing Science, 26 (2) , 101-14.

Hair, Jr. J. F., Anderson, R. E., Tathan, R. L. \& Black, W. C. (2006). Multivariate data analysis. Prentice Hall International, Inc. USA.

Hasibuan, M. (2001). Manajemen Sumber Daya Manusia: Pengertian. Dasar, Pengertian, dan Masalah. Jakarta: PT. Toko Gunung Agung.

Jogiyanto. (2004). Metodologi Penelitian Bisnis: Salah Kaprah dan Pengalaman Pengalaman. Yogyakarta : BPFE

Kelley, S. (1992). Developing customer orientation among service employees. Journal of the Academy of Science, 20 (1), 27-36.

Kelley, S. W. \& Hoffman, K. D. (1997), An Investigation of Positive Affect, Prosocial Behaviors and Service Quality, Journal of Retailing, 73, 407-427

Kotler, P. (2000). Marketing management $10^{\text {th }}$ ed. New Jersey : Prentice Hall

McKenzie, S. B., Podsakoff, P. M., \& Ahearne, M. (1998). Some possible antecedents and consequences of in-role and extra-role salesperson performance. Journal of Marketing, 62, 87-98.

Morrison, E.W. (1996). Organizational citizenship behaviour as a critical link between HRM practices and service quality. Human Resource Management, 35, 493512.

Netemeyer, R.G., Boles, J.S., Mckee, D.O., \& McMurrian, R. (1997). An investigation into the antecedents of organizational citizenships behaviours in a personal selling context. Journal of Marketing, 61, 85-98.

Organ, D. W. (1983). The applied psychology of work behavior. Texas: Business Publication.inc

Parasuraman, A., Zeithaml, V., \& Berry, L. (1991). Refinement and reassessment of the SERVQUAL scale. Journal of Retailing, 67(4), 420-51.

Robbins, S. P. (2001). Organizational behaviour $9^{\text {th }}$ ed. Prentice Hall International, Inc.

Rotundo, M., \& Sacket, P. R. (2002). The relative importance of task, citizenship, and counterproductive performance to global ratings of job performance: A policycapturing approach. Journal of Applied Psychology, 87, 66-80.

Zeithaml, V. A., Berry, L. L. \& Parasuraman, A. (1996). The behavioral consequences of service. Quality Journal of Marketing, 60, 31-46. 